\title{
Method of continuous improvement of multidisciplinary programs and outreach activities
}

Marcelo S. Nogueira, Jacqueline Gunther, Katarzyna Komolibus, Sinéad M. Ryan, Brian Murray, et al.

Marcelo S. Nogueira, Jacqueline E. Gunther, Katarzyna Komolibus, Sinéad M. Ryan, Brian Murray, Moises A. Jezzini, Declan Kennedy, Stefan AnderssonEngels, "Method of continuous improvement of multidisciplinary programs and outreach activities," Proc. SPIE 11143, Fifteenth Conference on Education and Training in Optics and Photonics: ETOP 2019, 111432C (2 July 2019); doi: $10.1117 / 12.2523352$ 


\title{
Method of continuous improvement of multidisciplinary programs and outreach activities
}

\author{
Marcelo S. Nogueira ${ }^{1,2, *}$, Jacqueline E. Gunther ${ }^{1}$, Katarzyna Komolibus ${ }^{1}$, Sinéad M. Ryan ${ }^{1}$, \\ Brian Murray ${ }^{1,2}$, Moises A. Jezzini ${ }^{1,2}$, Declan Kennedy ${ }^{3}$, and Stefan Andersson-Engels ${ }^{1,2}$ \\ ${ }^{1}$ Tyndall National Institute, Lee Maltings, Dyke Parade, Cork, Ireland, T12 R5CP \\ ${ }^{2}$ University College Cork, Department of Physics, College Road, Cork, Ireland, T12 K8AF \\ ${ }^{3}$ University College Cork, Department of Education, College Road, Cork, Ireland \\ * Corresponding author \\ E-mail address: marcelosaitonogueira@gmail.com
}

\begin{abstract}
The growth of the global photonics market and technology investment creates a need for skilled professionals with multidisciplinary knowledge. The development of a successful multidisciplinary training for these professionals requires special attention to the implemented educational approaches. Current methods of multidisciplinary teaching and learning include tutoring by a team of experts of different backgrounds and development of projects among multidisciplinary teams of students. In these cases, a detailed feedback is needed from students and teachers in order to improve the course and keep a consistent alignment among the learning outcomes, teaching strategy, and evaluation methods. In this study, we describe the implementation of a method based on continuous improvement of multidisciplinary outreach activities and undergraduate programs. We illustrate the results of this implementation by showing samples of the feedback we received from students and teachers. The overall quality of the teaching and the content of the subject matter was perceived as good by students. Teachers' evaluation showed students' knowledge and behavior was satisfactory and the learning outcomes were achieved. Based on this, we believe our educational approach could improve the development and implementation of multidisciplinary activities.
\end{abstract}

Keywords: Education, photonics, biophotonics, outreach, teaching and learning, optics, optics and photonics, tissue optics.

\section{INTRODUCTION}

Multidisciplinary professionals are in high demand due to the increasing need for better solutions achieved through collaboration in diverse teams ${ }^{1,2}$. This demand impacts undergraduate programs worldwide, since they may be selected based on their abilities of integrating several disciplines together to solve real-life problems. Current methods of multidisciplinary teaching and learning are specific to the undergraduate courses and subjects they are applied to. These methods can include several types of diversity such as tutoring by a team of experts of different backgrounds ${ }^{3}$ and development of projects among multidisciplinary teams of students ${ }^{1}$. In these cases, multiple disciplines are combined in one curriculum or outreach activity, which may be targeted to a diverse audience in terms of background and educational level.

The implementation of multidisciplinary modules and courses may be difficult because of the trade-off between the learning breadth and depth ${ }^{4-7}$, which must be carefully balanced for optimized student outcomes and professional development $^{8}$. In addition, the connection between students' background and multidisciplinary topics, or the communication between professionals of different disciplines may impact the progress of activities. This connection may be difficult to be perceived by students, as there may be no logical sequence between the multidisciplinary activities and the development of the courses students are taking. In cases when the practical activities are required, teaching may be limited to what is allowed by the facilities and the policy of each institution. This policy may concern aspects such as clinical practice, research ethics, cell studies, and ideas subject to patentability. 
In this context, a method of continuous improvement can help the development and standardization of multidisciplinary programs and outreach activities. Given the broad spectrum of the audience and topics involved in the teaching and learning process, designing teaching strategies and activities to satisfy each learning style, as well as assessing students and teachers opinions about the course can be important to ensure enough information was collected for overall improvement in the next iteration of the course ${ }^{1}$.

An instructive method involving constant monitoring of the outcomes of each course section, as well as inclusive approaches for course design and assessment ${ }^{1,9}$ could bring adaptability to multidisciplinary courses and outreach activities by keeping the right balance between the diversity and depth of the content delivered to students. In this case, the feedback provided by teachers and students after front-end, formative, and remedial evaluation ${ }^{9}$ is essential to achieve continuous improvement of the activities on the course structure and teaching strategy ${ }^{10-12}$.

The module evaluation and structure differ for multidisciplinary outreach activities and programs. During outreach activities, a short time is allocated for content delivery, which needs to be well structured and focus on generating public interest in learning instead of achieving results in the exams (summative assessment). On the other hand, multidisciplinary programs have longer duration and more objective data should be assessed according to the guidelines of the accreditation organizations (e.g. ABET, Accreditation Board for Engineering and Technology). Also, the content should be covered indepth and have a logical sequence throughout the designed courses and curriculum. Despite the differences between multidisciplinary programs and outreach activities, continuous improvement is possible when progress can be monitored by the regular feedback about students' learning and teachers' communication. This also allows shifting the undergraduate education to a learning paradigm instead of an instructional one ${ }^{13}$.

Previous works have shown case studies of multidisciplinary teaching and learning in dentistry (case-based learning $)^{3}$, sustainable engineering (students perceptions on course content knowledge and perceptions) ${ }^{1}$, anatomy (review of studies for conceptualization and implementation of integrated a multimodal-multidisciplinary teaching approach ${ }^{2}$, cancer treatment (development of a board game) ${ }^{14}$, waste management, habitat design, technical writing, modelling and design of biological systems (description of case studies) ${ }^{15}$, conceptions of energy (student-generated analogies) ${ }^{16}$. However, none of those studies suggested a technique that incorporates the common aspects of multidisciplinary settings for general use in short events or undergraduate courses.

With this in mind, an inclusive education method that allows a variety of activities and assessment methods can be useful for satisfying the learning requirements of a diverse and adapt the course or module structure according to the regular feedback received. In this study, we present the implementation of one of these methods in a biophotonics workshop we developed in Tyndall National Institute. The workshop was delivered to 18 students over two days involving a variety of activities such as a lecture about biophotonics topics, visit to the laboratories, experimental activities, and computer exercises. The quality of several aspects of the workshop were highly rated. Also, we show an example of teachers' rates regarding the students' behavior and knowledge during the sections of the workshop, as well as achievement of the learning outcomes.

\section{METHODOLOGY}

\subsection{Audience and aim of the biophotonics workshop}

The biophotonics workshop was targeted to 18 students participating in the annual undergraduate and postgraduate summer student bursary program of the Irish Photonic Integration Centre (IPIC) at Tyndall National Institute. The program was designed to provide students with an immersive experience and insights into the photonics research environment. Then, students spent 10 weeks attending (not mandatorily) in workshops or talks and undertaking a photonics research project. Students with diverse backgrounds (from biomedical sciences, over instrument engineering to astrophysics) and educational levels were present at the workshop. The biophotonics workshop was designed to provide students with an overview of the biophotonics field and foster their interest in pursuing a career within the field or related area.

\subsection{Learning outcomes}

After successful completion of the workshop, students should be able to conceptualize general ideas about biophotonics and biomedical optics, as well as to understand the future potential of these fields. Essential (mandatory) 
learning outcomes in the cognitive domain included specific knowledge for exemplifying how biophotonics can contribute to other fields of study and vice versa and explaining how to estimate biomolecule concentrations in complex media and its clinical importance. Also, essential learning outcomes in the affective domain comprised co-operating with colleagues and teachers to solve biophotonics exercises, while outcomes in the psychomotor domain involved performing laboratory practical work in the area of biophotonics in an efficient and safe manner, and displaying appropriate computer skills in carrying out computer-based activities. Several desired learning outcomes involving more specific knowledge such as describing biophotonics applications in micro and macroscales were also included.

\subsection{Workshop structure}

The biophotonics workshop was executed within a total of 7 hours of activities on two days. The first day comprised a lecture of 2 hours and half an hour of visit to the biophotonics laboratories. The second day involved 1.5 hours experimental activities (figure 1, left side) and 1.5 hours of computer exercises (figure 1, right side). In order to accommodate the number of students for the second day activities, they were divided into two groups. We designed a userfriendly computer app to help students to perform simulations of optical properties of biological tissues and respective light fluence rates (i.e. the radiation incident on the cross section of a sphere, expressed per unit surface area and per unit time) for given properties and geometrical settings. The app required no prior programming experience and details are described elsewhere ${ }^{17-19}$.
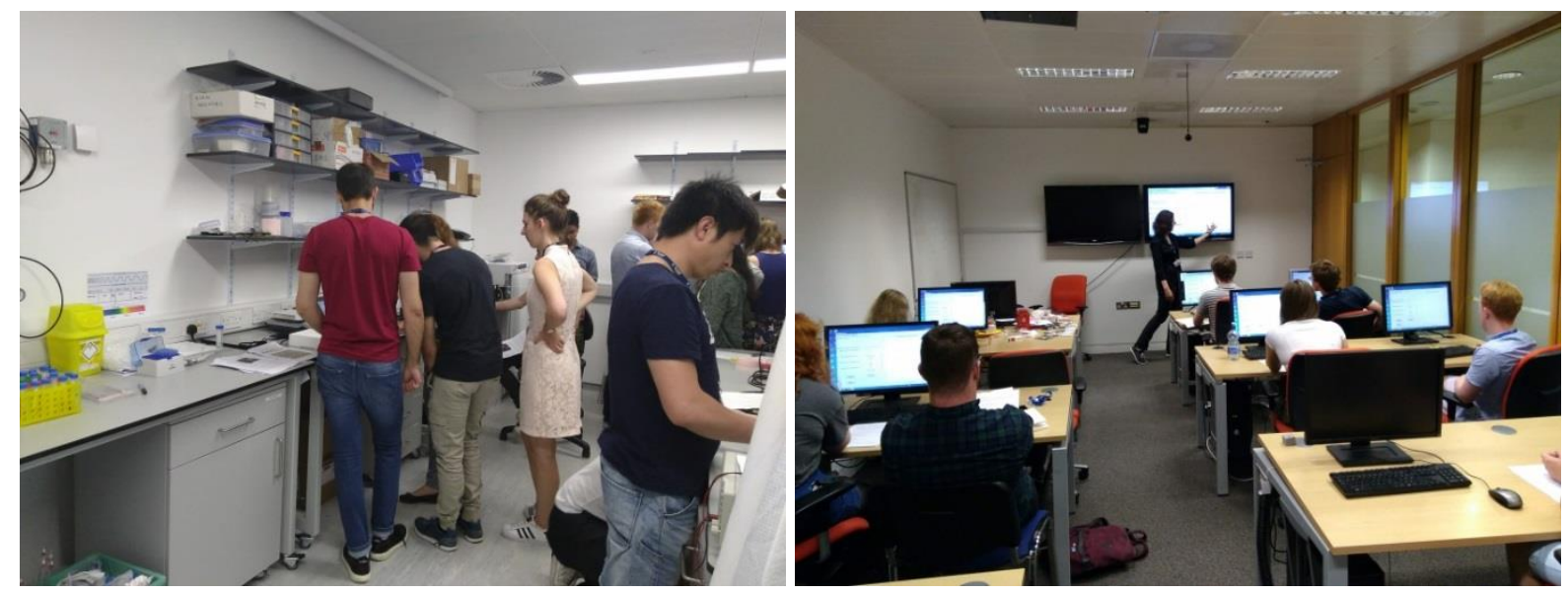

Figure 1: Left: experimental activities were carried out in the biophotonics laboratory. Right: computer-based activities were carried out in a computer laboratory.

\subsection{Feedback questionnaire and interview}

Qualitative and quantitative information about students' perceptions were collected on an anonymous feedback questionnaire at the end of the workshop and structured interviews two weeks later. The questionnaire included questions for the quality of subject matter and teaching of several parts, explanations and interest of the workshop in general. The interviews contained more specific questions about students' opinions and suggestions, as well as opinions about their learning. Teachers' evaluation was provided by an anonymous questionnaire about students' behaviour and interest in the sections of the workshop, achievement of learning outcomes, and effectiveness of the teaching strategy. The teachers provided evaluations for the whole group of students after the workshop, as summative assessment through exams might place too much focus on achieving results in the exam instead of developing students' interest in biophotonics. 


\section{RESULTS AND DISCUSSION}

In this paper, we present some examples of the diverse quantitative data we collected and motivate how these can be useful for multidisciplinary courses and outreach activities. We present some samples of students' feedback about the quality of the content of the subject matter and teaching in the biophotonics workshop. Students' opinions are shown in the comments of about the quality aspects. Samples of teachers' evaluation of students' behaviour, knowledge, and achievement of mandatory learning outcomes are illustrated.

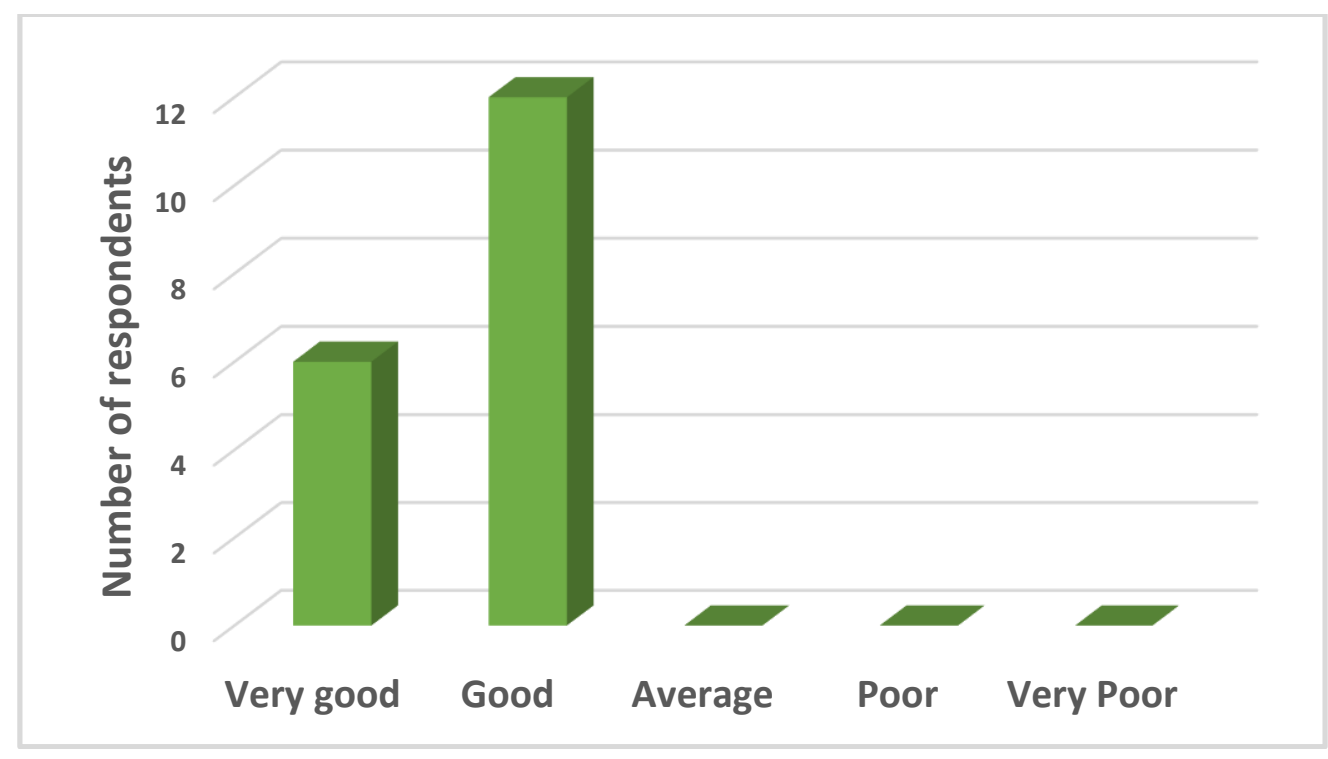

Figure 2: Number of respondents for each possible answer about the quality of the content of the subject matter in the biophotonics workshop.

Figure 2 shows the quality of the content of the subject matter in the biophotonics workshop was rated "very good" or "good" by students. More information is indicated in the following comments and suggestions by students:

- $\quad$ Very interesting

- Interesting

- Very relevant to my project here in Tyndall

- Well presented

- Very interesting

- The content could have been a bit more advanced

- Instructors were knowledgeable and covered a lot of content

- It was interesting

- Wide range of technologies/methods, very informative

- Informative without becoming 'bogged down' in very fine details. Relevant to my own studies but with new material (Biology etc.)

The quantitative information and corresponding comments about the quality of the content of subject matter suggests students perceived the content covered during the biophotonics workshop as interesting and relevant to the projects they were developing in Tyndall National Institute. 


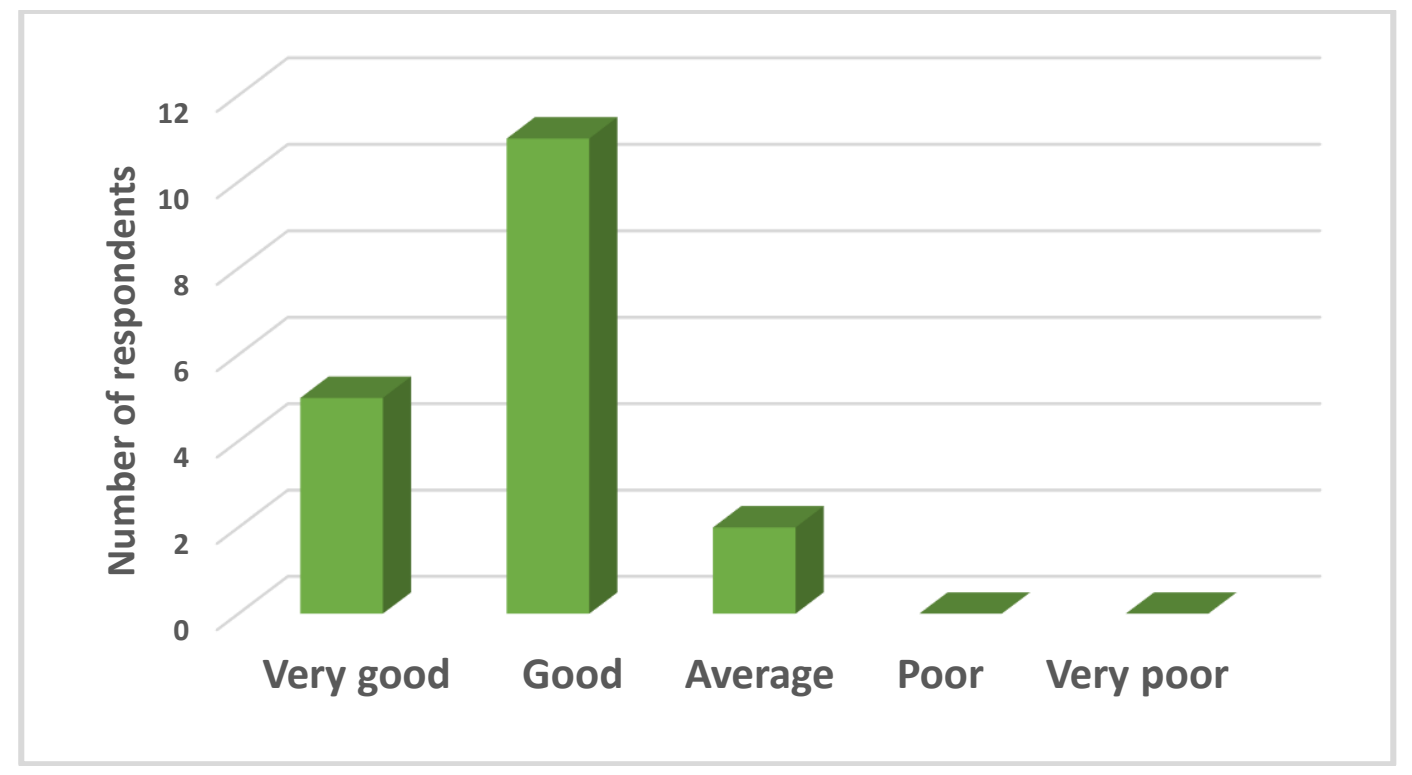

Figure 3: Number of respondents for each possible answer about the quality of teaching in the biophotonics workshop.

Figure 3 indicates most of the students considered the quality of the teaching in the biophotonics workshop as "very good" or "good". Comments and suggestions associated to this quality are provided below:

- Everything was clearly explained

- Very friendly and helpful

- Well explained

- Engaging

- Practical was the best part

- Instructors at times could be quiet and hard to hear

- Having experiments made it more interesting to learn and easier to remember

- Sometimes a bit quiet but overall good

- $\quad$ Some terms (e.g. medical) not clearly explained, that might be just my lack of knowledge in the area though

- Speakers were clearly enthusiastic and were friendly and approachable (with questions etc.).

Based on the comments and students evaluation of the quality of teaching during the workshop, our results indicate our teaching strategy was effective in terms of explanations, engagement, and developing students' interest. Limitations may have been generated by the high amount of information to be taught during a short event. 


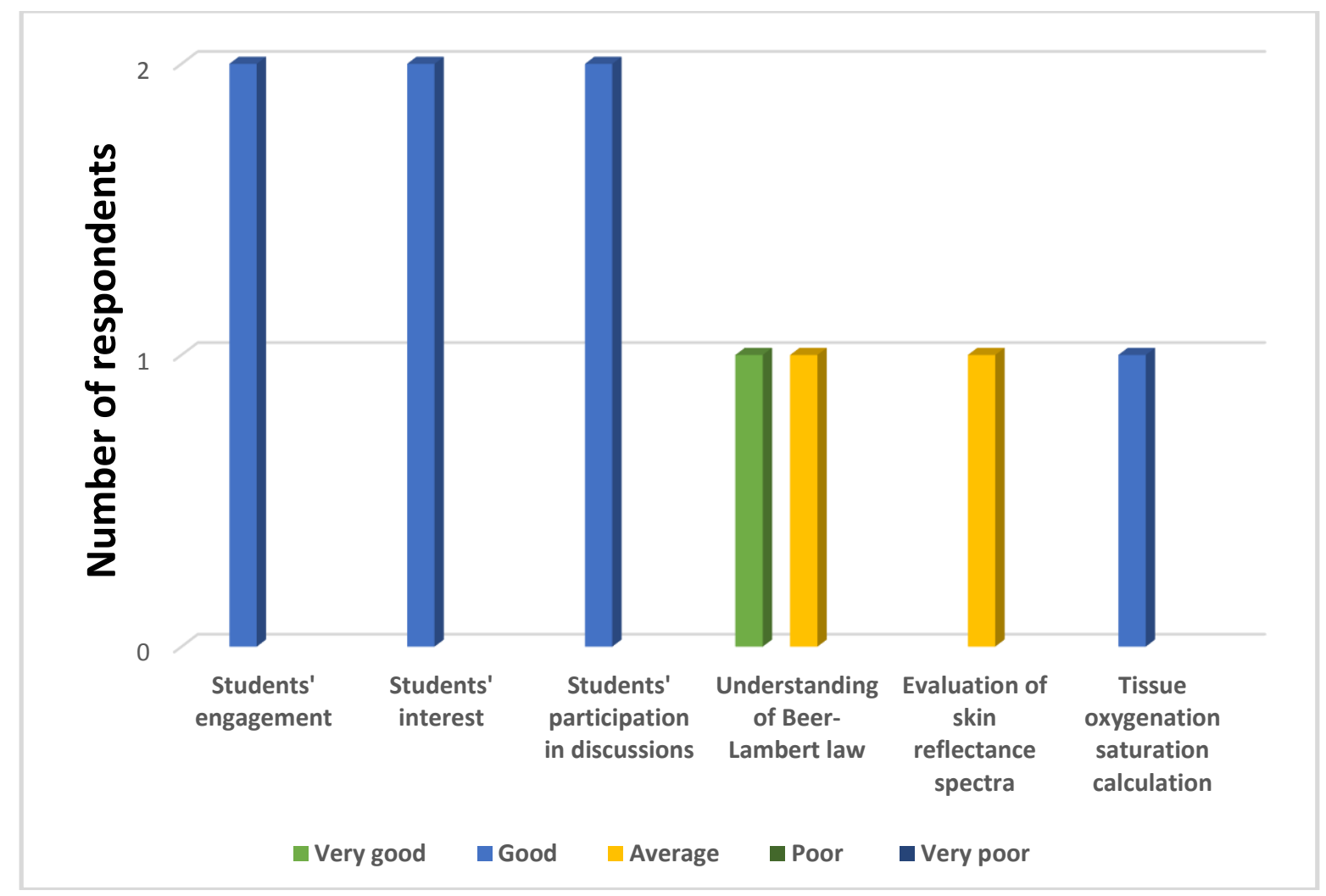

Figure 4: Number of respondents for aspects of students' behaviour and knowledge about the topics covered in the experimental activities.

Figure 4 shows the students' engagement, interest and participation were good during the experimental activities. In addition, the evaluation of successful performance of each part of the experimental activities indicated students were performed well on them. Teachers' impressions are shown below:

- I was present only for the Beer-Lambert Law experiment. The students appeared to be quite slow in using the pipette, due to a lack of experience in biological and chemical lab settings.

- Students were quite engaged in the lab activities, they worked well in the groups. There were a few students with a particular interest and they were asking majority of the questions and were involved in the discussions during and after each activity. Some of them weren't involved at all.

The teachers' opinions evidence time limitations during the experimental activities and lack of interest of part of the group of students, which may be the source of the "average" rating of students' knowledge aspects. However, the students were overall engaged in the laboratory activities. 


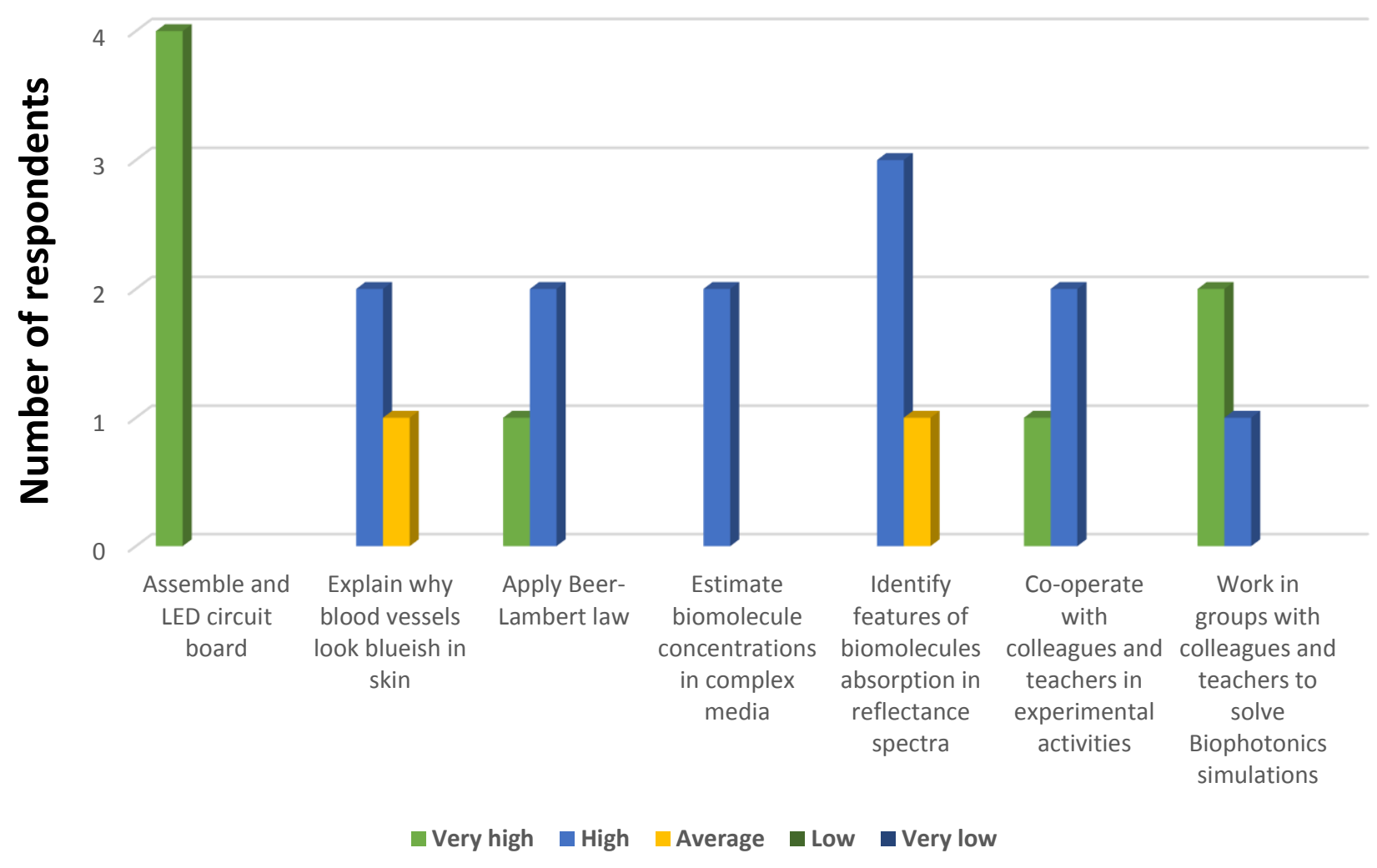

Figure 5: Number of respondents for the success level of the students' in achieving a list of essential (mandatory) learning outcomes.

Figure 5 shows the success level of the students in achieving each of the essential (mandatory) learning outcomes was mostly "high" or "very high". This suggests teachers were confident about students learning and skills gained after the workshop.

Our study illustrates the detailed feedback that could be acquired for improving multidisciplinary short events such as outreach activities. The feedback provided will be used to improve the workshop in the next iteration so that learning outcomes, teaching strategy, and assessment methods will be improved and continue aligned. By applying the modification after data analysis, we applied an instructive method for continuous improvement of the biophotonics workshop. This approach can be translated to multidisciplinary programs by regularly following up students learning and perceptions about the course, as well as teachers' evaluation about the accomplishment of the learning outcomes, students' behaviour, knowledge, and attitude.

Previous studies have developed solutions for multidisciplinary settings such as case-based learning, games, studentgenerated analogies, and application of multiple types of assessment in one course. Lancor et. al. suggested studentgenerated analogies can be used as formative assessment for instructors to understand how students "conceptualize

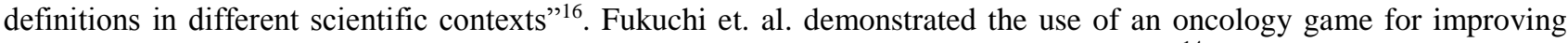
students' knowledge, participation, self-directed learning, and student-student interactivity ${ }^{14}$. Garvey et. al. suggested a case-based learning for practical activities where groups of students solve specific clinical-case problems with the expert in the area of each case ${ }^{3}$. Sharma et. al. proposed a multiple assessment approach for evaluating student perceptions and learning ${ }^{1}$. This was performed by collecting qualitative and quantitative information through focus groups (front-end evaluation $^{9}$ ) and pre and post-assessment. These information was valuable for teachers to measure student learning and understand the strengths and weaknesses of the applied teaching approach. The overall results could be used for improving the course in the next iteration.

With this in mind, an educational method for continuous improvement involving an inclusive approach can be used to address the needs of different learning styles. This approach should include a variety of activities to explain concepts 
related to each other and teaching strategies that are compatible with the learning outcomes and assessment methods. The feedback received by students and teachers should be analysed in order to implement improvements in the structure and teaching strategy of the course or outreach activity. In the case of multidisciplinary undergraduate courses, the implementation should take into account the requirements of the accreditation organizations and the sequence of modules to be taken as part of the curriculum. Special attention must be taken when integrating a multidisciplinary course in the curriculum, as its outcomes should clearly benefit the professional development of students. This can be done by exposing the relationships of the multidisciplinary course with other modules of the curriculum and pointing out any change associated with students' feedback on the previous course iterations.

\section{CONCLUSIONS}

In this paper, we described aspects of the implementation of an inclusive education method with a variety of activities and assessment methods that can be used for outreach activities or multidisciplinary undergraduate programs. Students' feedback suggested our biophotonics had good quality of teaching and the content of the subject matter. Teachers' evaluation showed students' knowledge and behavior was satisfactory and the learning outcomes were achieved. The educational approach of continuous improvement we describe can be used in other multidisciplinary settings provided that teachers design activities based on the constructive alignment among learning outcomes, teaching strategy, and evaluation methods.

\section{ACKNOWLEDGEMENTS}

We acknowledge Dr. Tomas Svensson and Dr. Johan Axelsson for providing material on which we based our computer exercises. This research was financially supported by Science Foundation Ireland (SFI Professorship award SFI/15/RP/2828, SFI Research Centre award SFI 12/RC/2276).

\section{REFERENCES}

[1] Sharma, B., Steward, B., Ong, S. K. and Miguez, F. E., "Evaluation of teaching approach and student learning in a multidisciplinary sustainable engineering course," J. Clean. Prod. 142, 4032-4040 (2017).

[2] Johnson, E. O., Charchanti, A. V and Troupis, T. G., "Modernization of an anatomy class: From conceptualization to implementation. A case for integrated multimodal--multidisciplinary teaching," Anat. Sci. Educ. 5(6), 354-366 (2012).

[3] Garvey, M. T., O’Sullivan, M. and Blake, M., "Multidisciplinary case-based learning for undergraduate students," Eur. J. Dent. Educ. 4(4), 165-168 (2000).

[4] Collins, A., "Design issues for learning environments," Int. Perspect. Des. Technol. Learn. Environ., 347-361 (1996).

[5] Scott-Little, C., Kagan, S. L. and Frelow, V. S., "Inside the Content: The Breadth and Depth of Early Learning Standards.," SERVE Cent. Contin. Improv. UNCG (2005).

[6] Coker, J. S., Heiser, E., Taylor, L. and Book, C., "Impacts of experiential learning depth and breadth on student outcomes," J. Exp. Educ. 40(1), 5-23 (2017).

[7] Schwartz, M. S., Sadler, P. M., Sonnert, G. and Tai, R. H., "Depth versus breadth: How content coverage in high school science courses relates to later success in college science coursework," Sci. Educ. 93(5), 798-826 (2009).

[8] Wicklein, R. C. and Schell, J. W., "Case studies of multidisciplinary approaches to integrating mathematics, science and technology education.,” J. Technol. Educ. 6(2), 59-76 (1995).

[9] Allen, S., Campbell, P. B., Dierking, L. D., Flagg, B. N., Friedman, A. J., Garibay, C. and Ucko, D. A., "Framework for evaluating impacts of informal science education projects," Rep. from a Natl. Sci. Found. Work. (2008).

[10] Pereira, D., Flores, M. A., Simão, A. M. V. and Barros, A., "Effectiveness and relevance of feedback in Higher 
Education: A study of undergraduate students," Stud. Educ. Eval. 49, 7-14 (2016).

[11] Holmes, N., "Student perceptions of their learning and engagement in response to the use of a continuous eassessment in an undergraduate module," Assess. Eval. High. Educ. 40(1), 1-14 (2015).

[12] Wong, B. M., Etchells, E. E., Kuper, A., Levinson, W. and Shojania, K. G., "Teaching quality improvement and patient safety to trainees: a systematic review," Acad. Med. 85(9), 1425-1439 (2010).

[13] Barr, R. B. and Tagg, J., "From teaching to learning-A new paradigm for undergraduate education," Chang. Mag. High. Learn. 27(6), 12-26 (1995).

[14] Fukuchi, S. G., Offutt, L. A., Sacks, J. and Mann, B. D., "Teaching a multidisciplinary approach to cancer treatment during surgical clerkship via an interactive board game,” Am. J. Surg. 179(4), 337-340 (2000).

[15] Christy, A. D. and Lima, M., "Developing creativity and multidisciplinary approaches in teaching Engineering problem-solving," Int. J. Eng. Educ. 23(4), 636 (2007).

[16] Lancor, R. A., "Using student-generated analogies to investigate conceptions of energy: A multidisciplinary study,” Int. J. Sci. Educ. 36(1), 1-23 (2014).

[17] Nogueira, M. S., Gunther, J., Komolibus, K. and Andersson-Engels, S., "Teaching light-tissue interactions: using technology for education,” Opt. Interact. with Tissue Cells XXX 10876, 108761H (2019).

[18] Saito Nogueira, M. and Gunther, J. E., "MATLAB code for generation of the tissue optics app," <https://codeocean.com/capsule/8436fcf0-ff83-4f90-9d1b-ab1219ad8d21/code> (13 January 2019 ).

[19] Saito Nogueira, M. and Gunther, J. E., "Tissue optics app developed and tested by Biophotonics@Tyndall," <https://drive.google.com/drive/folders/1I64dnU3Q1 zz8kjMUx162oha4w2UPSxpq?usp=sharing> (13 January 2019 ). 